\title{
A Survey: Virtual, Augmented and Mixed Reality in Education
}

\author{
Sumit Patel \\ Surat, Gujarat
}

\author{
Binal Panchotiya \\ Surendranagar, Gujarat
}

\author{
Akashkumar Patel \\ Department of Information Technology \\ Devang Patel Institute of Advance, \\ Technology and Research-(DEPSTAR), \\ Faculty of Technology (FTE), \\ Charotar University of Science and Technology \\ (CHARUSAT), Changa, Gujarat
}

\author{
Aishwariya Budharani \\ Devang Patel Institute of Advance, \\ Technology and Research-(DEPSTAR), \\ Faculty of Technology (FTE), \\ Charotar University of Science and Technology \\ (CHARUSAT), Changa, Gujarat
}

\begin{abstract}
Shivam Ribadiya
Devang Patel Institute of Advance, Technology and Research-(DEPSTAR), Faculty of Technology (FTE), Charotar University of Science and Technology (CHARUSAT), Changa, Gujarat
\end{abstract}

\begin{abstract}
In the upcoming era of technology Virtual Reality and Augmented Reality are not new eye catching technology but still it has some limitations to put a stop for actual enactment. It is true that the progress of new technologies has made it more beneficial to afford the hardware and software made available $A R, V R$ and MR in the number of domains including education. The nature of technologies provides a number of opportunities. It may help from traditional allocation of separate lessons to take care of pastoral responsibility to learning concepts. These technologies fulfill the needs of learners in the technological century. It reinvents the door of education and makes the education field interactive using appropriate virtual settings. This discussion of this works includes the reinvention of education using AR, VR and MR technologies. Its modified way of education fills the needs of practical lessons.
\end{abstract}

Keywords-Augmented Reality, Education, Mixed Reality, Virtual Reality.

\section{INTRODUCTION}

Nowadays, Virtual reality (VR) and Augmented Reality (AR) are often presented as a kind of futuristic technologies and come up with the integration of computer software, hardware and virtual world technology. These technologies are not actually fresh concepts. It has been around for years, however still having mystery for many people. Virtual reality first introduced in mid-1980 by Jaron Lanier [1]. Virtual reality provides a simulated digital environment that is an absolute replacement of the actual real world using sensory equipment and computers such as gloves and handsets [2]. VR - virtual reality forms the immediate after real time communication between design virtual world and people [3]. These dynamic environments show the real world and make reactions according to the people's form. Therefore, since a few years' technology has changed drastically and takes up more attention from companies and researchers. Interestingly, AR is an addition of virtual reality [4]. AR overlaying digital content on the environment around you by assigning virtual objects in the real world. Virtual objects may be in different forms: images, videos or other interactive data [5]. Augmented reality discovered by David Mizell and Thomas Caudell in 1990 [6].
An AR technique ought: (1) Merge virtual and real objects in a real environment; (2) execute interactively in real-time; (3) register virtual and real objects with each one [7][8][9]. The difference between AR and VR is that the VR era makes an environment in which the individual feels and appears to be shifting through simulated experiences generated by computers in the comparably way as individuals move through a native environment. Though immersed within the virtual global world, the individual can't distinguish the actual world that still surrounds them. On other hand, AR permits. The people to watch and gain experience of the physical world, augmenting it with superimposed intently virtual objects. In different words, while VR replaces fact, AR supplements it, forming an environment in which real and virtual objects coexist in harmony [10]. Mixed Reality (MR) combines the digital world with the physical world where both can interact and exist together [11]. It is also known as "Hybrid Reality". MR was originally invented in 1994 by Fumio Kishino and Paul Milgram [12]. Mixed reality is the subsequent advancement in computer, surroundings interaction and explores possibilities previously restricted to our imaginations [13]. Moving around the virtual objects may even give you different perspectives and angles too. In contrast, MR would permit a person to interact with virtual objects and manipulate them as if they were at the same location as them. In other words, MR gives a feel like one hand or foot of a user in an imaginary place and another in the real global world [14]. The difference between VR, AR and MR is shown in figure 1 [15]. An umbrella term that includes an assortment of technologies that enhance or intensify our senses is called Extended Reality (XR) [16]. XR provides a number of information by virtual worlds through creating a totally unreal illusory environment for us to take a drive directly to the real world experience [17]. 


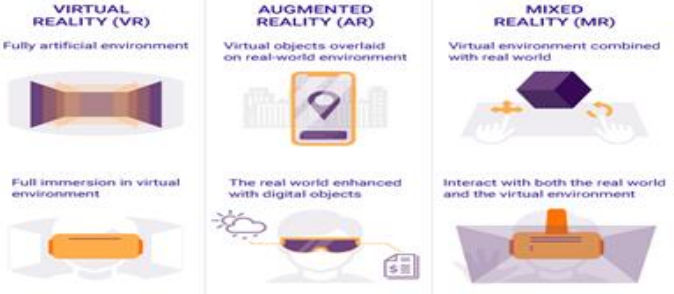

Figure 1 Difference Between VR, AR and MR [15]

$\mathrm{XR}$ is a field that unification of phenomenal elements that cover AR, VR, and MR to provide new vision to learn new language in technocrats of the global village [18]. Extended reality is a new sensation technology along with VR, AR, and MR. Extended reality is a new sensation technology along with VR, AR, and MR shown in figure 2 [19].

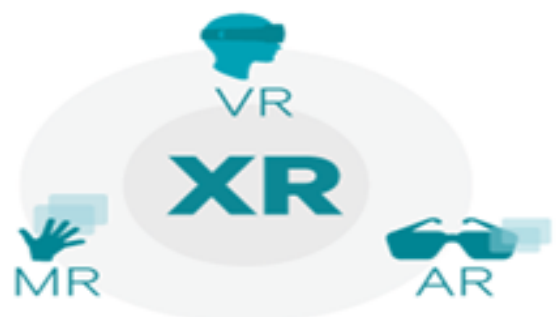

Figure 2 Extended Reality Diagram [19]

The real life application of VR, AR, and MR: The wide range applications of virtual reality are education [20], marketing [21], real estate [22], Agriculture science [23], etc. Augmented reality accepted by many fields are aeronautical maintenance [24], navigation [25], games [26], education [27], etc. The mixed reality used in many applications like medical and health-care [28], education and entertainment [29], etc.

\section{HOW PEOPLE CAN BRING VR, AR AND MR EXPERIENCES TO LIFE?}

\section{A. Virtual Reality}

In virtual reality individuals get an experience of artificial sightseeing with sound and feel the manmade digital world.

The computer generated world opening your eyes by imagination and interesting provides a way to see a computergenerated or computer simulated world all around you. In this environment interaction is made easy [29]. Hence, you can easily make a move in this computerized world and interaction. These are the reasons virtual reality makes more likes.

There are two types of headsets used to immerse individuals in VS. Virtual Reality headsets: (1) PC-connected headsets and (2) Standalone headset [30]

\section{- PC-connected headsets}

As their name "PC-connected headsets" recommends, these VR headsets are connected to a gaming platform or other computer that gives high definition resolution virtual simulated experiences. The operational power of processing modern technology computers is speedy. Hence, they can generate persuasive digital and realistic worlds. VR headsets handle with special controllers. In this situation, Individuals can actually directly interact with the computer generated virtual environment they're plunged into. It may be expected that personal computers - connected headsets - give better involving VR experiences. The most well liked PC - connected VR headsets are Samsung Odyssey+, Oculus Quest, HTC Vive, and PlayStation VR [31].

\section{- Standalone headsets}

Another type of virtual reality is Standalone headsets. In a market computer connected VR headsets are quite more expensive to individuals. Due to that reason comparatively less number of people are able to drop cash in the tech savvy world to take home. So, the solution of high cost handsets is a different way to get benefits of VR - using standalone headsets. It does not need any types of connection to any console or computer machine. The majority of standalone Virtual Reality headsets access a Smartphone to give the benefits of VR experience to individuals. That equipments are quite cost-effective, as individuals can simply put their smartphone in a standalone headset device to take advantage of VR in any field of technology. The given devices work exactly in this way such as Oculus Quest VR [32], Lenovo mirage solo [33], Google Daydream [34], Google Cardboard [35], and Samsung Gear VR [36], etc.

\section{B. Augmented Reality}

There are two such ways to bring AR experience to individual life. With AR, users bring experiences to life using (1) Smart glasses and AR headsets [37] and (2) portable devices [38].

\section{- Smart glasses and AR headsets}

First way to form AR experiences is to practice AR headsets or smart glasses. As opposed to VR handsets, these headsets and glasses don't drench clients into a completely designed virtual simulated environment however, fair include computerized objects to the genuine world. For instance, using glass, virtual information is anticipated right before the user's eyes.

\section{- portable devices}

The second one is a portable device. As individuals can utilize their tablets or smartphones to run AR applications, AR is the foremost open reality innovation. After capturing the real world images through phone cameras in virtual objects, AR apps overlaid. Furthermore, people can see the changes on their own Smart device. For example, Pokémon Go. Billions of people play this game and follow the virtual Pokemon to catch, which can display on their smartphones Screens.

\section{C. $\quad$ Mixed reality}

Now, which devices are required for MR Experience to life? The main two devices are Holographic Devices and Immersive Devices.

\section{- Holographic Devices}

The translucent glasses take place in holographic headsets which permits the user to see and feels the surroundings. Hologram creates virtual experiences. For example, Microsoft launched Microsoft HoloLens in 2016. Hololens head - mounted see-through display device is able to carry out a spatial mapping and can display 3D holograms precisely in specific environments [39]. 


\section{- Immersive devices}

Immersive devices provide non-translucent displays which block the real world completely. These devices use cameras for tracking. For example, Acer [40] and HP [41] provides Windows mixed reality headsets.

\section{HOW VIRTUAL REALITY, AUGMENTED REALITY AND MIXED REALITY ADOPTED BY EDUCATION?}

In the curriculum of education, students are facing a dilemma with the necessity of abstract thinking approach, concepts and understanding due to the complexity [42]. The courses of education generally refer to the procedure of easy learning to acquire information and achieve optimistic principles by skills [43].

\section{A. Virtual Reality in Education}

The number of educational corners around the globe has begun to establish modern and powerful innovative tools built on technologies. It fulfills the necessity of manifold the number of students. From the decades, professional development is taking place with virtual reality (VR) from purview gaming. In the science courses, many students face the difficulty to understand the issues due to its uncertain technical error, significance of abstract thinking and those perceptions are not completely tactile present by Yager[44] and Zheng et. al [45].

Virtual reality is a great tool in supporting learning as well as facilitating teaching processes. Numerous literature and reports reported that maximum learners recalled the things which were seen during learning via virtual reality. These manuscripts determined that VR is better convenient and creates striking situations apart from laboratory or workshop related Practical sessions [46] [47] [48].

Virtual reality technologies offer educators the opportunity to handle pastoral responsibilities within the learning context apart from traditionally allocating separate lessons to accomplish specific requirements. In the field process of education, the classroom or the laboratory are more virtual platforms to simulate according to their needs. However, according to Charistou and C., This paper offers a harmless atmosphere to evaluate cases that would be too dangerous, hard to handle and execute in day-to-day life scenarios [49]. In reality, teachers also address the demands of new technology today in the tech-savvy world and expensive tools used in chemical reagents, robotics, medical materials and electronic components etc. For the results it replicates information in the form of $3 \mathrm{D}$ model with the appropriate physical properties of the system and conveyed to VR tools. Resultant into developing countries and communities around the globe by implementing difficult tasks [50]. The feature of VR plays a vital role in prepare students for the actual environment, while providing a means of making early indesign decisions profitably [51]. The main purpose of this technology to motivate and engage young students, by engaging in planning issues in current knowledge. A more innovative approach was given by Hurtdo et. al [52], in which designed VR tools for robotics training and education. In addition to, the application has a built in physics engine followed by detailed instructions and haptic feedback interaction takes place. To ease the process of creating VR musical skills for alternative ways proposed by Serafin et al. [53] hand gesture and other manual input devices. Students join the VR class in between PowerPoint screens behind them.

\section{B. Augmented Reality in Education}

Also, augmented reality is widely used in preschool education, childhood education, Secondary education and higher education. For a few decades, AR applications were positively adopted for development and learning in preschool education. Augmented creativity or AR as an imaginative technology for kids is a term introduced by [54]. The survey of Some research findings and state of the art method described here. Mohd Khalid Mokhtar et al. presented mobile based augmented reality for preschool learning [55]. The aim of this work is to increase attention and interest of kids to express and practice their own innovative abilities. For kids, it also offers coloring books with AR. Many other coloring books, such as Hunted book is the prime example of well integrated AR content in book [56]. Several coloring book products are established, for instance Feng et.al. proposed a computerized $2 \mathrm{D}$ to $3 \mathrm{D}$ cartoon interactive model to build various complex AR scenes [57]. Magic book is the prominent example of augmented reality for interactive book for the kids [58]. R. M. Yilmaz et. al. demonstrates the effective educational tools to expand preschool kid's listening and cognition skills [59]. Aguirregoitia Martínez et al promoted AR as an applicable technique for childhood learning. The main goal is to familiarize numbers, encourage the exploration of rich vocabulary and initiate reading in English as a second language. Furthermore, it may be enhancing the feeling of selfcompetence when a child gets a verification comment after each brief movement [60]. Arjun Bhadra et.al. presented ABCD 3D bimodal (scanning mode and vehicle mode) game based on AR to develop the awareness of print-based literacy in preschool-aged children [61]. Wu. et. al., discussed the analysis of AR research findings [62] that AR holds educationally convenient affordness in particular the ability to display 3D information and experience lessons within a situated sense. Barbara Schiavi et al invented an experimental protocol based on AR application for secondary education in history lesson. The aim of this work is to get input using AR to enhance secondary school student academics when conventional Documents absolutely not given sufficient effectiveness in terms of its ability to comprehend complex concepts. That helps to construct a 3D visual model based on a 2D image of an archeological site [63]. Orhan Yaman et.al proposed a software module based on image processing combined with augmented reality. Furthermore, users can optionally switch on the image processing module and observe the variations in image in real time [64]. In software engineering courses, Rebecca Reuter et.al. described identification of learning obstacles to provides all holistic information from both learners and teachers points of view [65]. D. Paredes-Velasteguí et.al. Invented learning- teaching activities based on experimentation and implementation of augmented reality application as a reinforcement tool. In these manuscripts the output was compared with the control group 
after the augmented method is applied to the experimental group [66]. Mesut Alptekin et. al. proposed augmented reality based application to build and extend functional capabilities in dealing with electro-technical laboratory components as well as equipment [67]. Asim Majeed et. al. proposed a framework by using Internet-of- Things (IoT) technology with augmented reality and cloud computing for university smart campus. Moreover, intra-communication is taking place through cloud computing, wearable technologies are assembling information with augmented reality and Several objects are joined with sensors [68]. Augmented reality is useful for collaborative learning. Chen [69] invented an AR based learning environment to illustrate the significance of peer interaction to promote chemistry learning for students.

Wagner, Schmalstieg, and Billinghurst [70] implemented a handheld game named virtuoso based on collaborative education in 2006.

\section{Mixed Reality in Education:}

Mixed reality similarly becomes a broadly popular practice in context of learning and education [71]. Earlier research findings indicate that mixed reality systems permits learners to more actively control their learning strategies [72]. M. V. Pridhvi Krishna proposed education and production training applications using mixed reality gadgets with depicts and condense trials in a smart computing system [73]

\section{CONCLUSION}

This manuscript defines the overview of virtual reality, augmented reality and mixed reality and how people are able to experience these technologies using devices. In addition, it also defines important development in the education field. In brief, VR is a completely computer-generated situation. AR is an actual environment surrounded by simulated objects. MR is an actual environment plus simulated objects with which you can communicate. Furthermore, Major players in VR includes PlayStation VR, HTC Vive, and Oculus Rift, AR includes AR headphones and smart glasses and MR includes Holographic Devices such as Hololens and Immersive Devices. Additionally, for decades' education system has been developed from preschool education to higher education. It has also been adjusting to the student's current technologies and needs. Here, define some research findings and state-of-the art approaches adopted by education. Finally, we can say that VR, $\mathrm{AR}$ and MR delivers excellent simulation which cannot be accessed in conventional classrooms. This is representative of the environment in which young generations are relaxed with experiences.

\section{REFERENCES}

[1] P. Fuchs, G. Moreau and P. Guitton, Virtual Reality: Concepts and Technologies, Boca Raton: CRC Press, Inc., 2011

[2] Huang, ShiMing, ChaoYang Fang, and Xue Mei. "Exploring the application of virtual reality technology in surveying and mapping archives." In 2015 23rd International Conference on Geoinformatics, pp. 1-4. IEEE, 2015

[3] Gandhi, Ronak Dipakkumar, and Dipam S. Patel. "Virtual realityopportunities and challenges." Virtual Reality 5.01 (2018).

[4] Cai, S., Wang, X., \& Chiang, F. K. (2014). A case study of Augmented Reality simulation system application in a chemistry course. Computers in human behavior, 37, 31-40.
[5] Bajura, M., Fuchs, H., \& Ohbuchi, R. (1992). Merging virtual objects with the real world: Seeing ultrasound imagery within the patient ACM SIGGRAPH Computer Graphics, 26(2), 203-210.

[6] Janin, A. L., Mizell, D. W., \& Caudell, T. P. (1993, September) Calibration of head-mounted displays for augmented reality applications. In Proceedings of IEEE Virtual Reality Annual International Symposium (pp. 246-255). IEEE.

[7] R. T. Azuma, "A survey of augmented reality," PresenceTeleoperators and Virtual Environments, vol. 6, no.4, pp. $355-385$, 1997

[8] T. H. Höllerer \& S. K. Feiner, "Mobile Augmented Reality". In H. A Karimi, \& A. Hammad (Eds.), Tele geoinformatics: Location-Based Computing and Services, pp. 392-421, 2004

[9] H. Kaufmann, H, "Collaborative augmented reality in education," in Proceeding of Imagina 2003 Conference, Monte Carlo, Monaco, 2003, pp. 1-4

[10] Hincapié, Mauricio, Andrea Caponio, Horacio Rios, and Eduardo González Mendívil. "An introduction to Augmented Reality with applications in aeronautical maintenance." In 2011 13th International Conference on Transparent Optical Networks, pp. 1-4. IEEE, 2011.

[11] Febretti, A., Nishimoto, A., Thigpen, T., Talandis, J., Long, L., Pirtle, J. D., ... \& Sandin, D. (2013, March). CAVE2: a hybrid reality environment for immersive simulation and information analysis. In The Engineering Reality of Virtual Reality 2013 (Vol. 8649, p 864903). International Society for Optics and Photonics.

[12] Milgram, Paul, and Fumio Kishino. "A taxonomy of mixed reality visual displays." IEICE TRANSACTIONS on Information and Systems 77, no. 12 (1994): 1321-1329.

[13] Rubio-Tamayo, Jose Luis \& Gértrudix, Manuel \& García, Francisco. (2017). Immersive Environments and Virtual Reality: Systematic Review and Advances in Communication, Interaction and Simulation. Multimodal Technologies and Interaction.

[14] Benford, S., \& Giannachi, G. (2011). Performing mixed reality. The MIT Press.

[15] https://rubygarage.org/blog/difference-between-ar-vr-mr\#article As on date $01 / 05 / 2020$.

[16] Rubin, P., Galaxy, G., Staff, W., Muncy, J., Parham, J., Ellis, E., \& Watercutter, A. (2018). The wired guide to virtual reality.

[17] Kohler, T., Fueller, J., Matzler, K., Stieger, D., \& Füller, J. (2011) Co-creation in virtual worlds: The design of the user experience. MIS quarterly, 773-788

[18] Ibanez, M., Kloos, C. D., Leony, D., Rueda, J. J. G., \& Maroto, D (2011). Learning a foreign language in a mixed-reality environment. IEEE internet computing, 15(6), 44-47.

[19] Flavián, C., Ibáñez-Sánchez, S., \& Orús, C. (2019). The impact of virtual, augmented and mixed reality technologies on the customer experience. Journal of Business Research, 100, 547-560.

[20] Kamińska, Dorota, Tomasz Sapiński, Sławomir Wiak, Toomas Tikk, Rain Eric Haamer, Egils Avots, Ahmed Helmi, Cagri Ozcinar, and Gholamreza Anbarjafari. "Virtual Reality and Its Applications in Education: Survey." Information 10, no. 10 (2019): 318.

[21] Ting, Chen. "The Applied Research on the Virtual Reality Technology in the Hotel Marketing Management." In 2019 International Conference on Smart Grid and Electrical Automation (ICSGEA), pp. 242-246. IEEE, 2019.

[22] Deaky, Bogdan-Alexandru, and Luminita Parv. "Virtual Reality for Real Estate: Its evolution in Bluemind Software." In 2017 4th Experiment@ International Conference (exp. at'17),pp. 83-86. IEEE, 2017

[23] Yu, Feng, Jun-Feng Zhang, Yousen Zhao, Ji-Chun Zhao, Cuiping Tan, and Ru-Peng Luan. "The research and application of virtual reality (VR) technology in agriculture science." In International Conference on Computer and Computing Technologies in Agriculture, pp. 546-550. Springer, Berlin, Heidelberg, 2009.

[24] Hincapié, Mauricio, Andrea Caponio, Horacio Rios, and Eduardo González Mendívil. "An introduction to Augmented Reality with applications in aeronautical maintenance." In 2011 13th International Conference on Transparent Optical Networks, pp. 1-4. IEEE, 2011

[25] Liu, Ding-Yu. "Combined with augmented reality navigation applications in the library." In 2016 International Conference on Advanced Materials for Science and Engineering (ICAMSE), pp. 441-443. IEEE, 2016

[26] Paavilainen, Janne, Hannu Korhonen, Kati Alha, Jaakko Stenros, Elina Koskinen, and Frans Mayra. "The Pokémon GO experience: A location-based augmented reality mobile game goes mainstream." In 
Proceedings of the $2017 \mathrm{CHI}$ conference on human factors in computing systems, pp. 2493-2498. 2017.

[27] Kesim, Mehmet, and Yasin Ozarslan. "Augmented reality in education: current technologies and the potential for education." Procedia-social and behavioral sciences 47 (2012): 297-302.

[28] Sankaran, Naveen Kumar, Harris J. Nisar, Ji Zhang, Kyle Formella, Jennifer Amos, Lisa T. Barker, John A. Vozenilek, Steven M. LaValle, and Thenkurussi Kesavadas. "Efficacy Study on Interactive Mixed Reality (IMR) Software with Sepsis Prevention Medical Education." In 2019 IEEE Conference on Virtual Reality and 3D User Interfaces (VR), pp. 664-670. IEEE, 2019.

[29] Hughes, Charles E., Christopher B. Stapleton, Darin E. Hughes, and Eileen M. Smith. "Mixed reality in education, entertainment, and training." IEEE computer graphics and applications 25, no. 6 (2005): 24-30.

[30] Yu, F., Zhang, J. F., Zhao, Y., Zhao, J. C., Tan, C., \& Luan, R. P. (2009, October). The research and application of virtual reality (VR) technology in agriculture science. In International Conference on Computer and Computing Technologies in Agriculture (pp. 546-550). Springer, Berlin, Heidelberg.

[31] Bamodu, O., \& Ye, X. M. (2013). Virtual reality and virtual reality system components. In Advanced materials research (Vol. 765, pp. 1169-1172). Trans Tech Publications Ltd.

[32] Mehrfard, A., Fotouhi, J., Taylor, G., Forster, T., Navab, N., \& Fuerst, B. (2019). A Comparative Analysis of Virtual Reality Head-Mounted Display Systems. arXiv preprint arXiv:1912.02913.

[33] Hillmann, C. (2019). Comparing the Gear VR, Oculus Go, and Oculus Quest. In Unreal for Mobile and Standalone VR (pp. 141-167). Apress, Berkeley, CA

[34] Huang, Y., Shakya, S., \& Odeleye, T. (2019). Comparing the Functionality between Virtual Reality and Mixed Reality for Architecture and Construction Uses. Journal of Civil Engineering and Architecture, 13, 409-414.

[35] Keene, S. (2018). Google Daydream VR Cookbook: Building Games and Apps with Google Daydream and Unity. Addison-Wesley Professional.

[36] Fabola, A., Miller, A., \& Fawcett, R. (2015, October). Exploring the past with Google Cardboard. In 2015 Digital Heritage (Vol. 1, pp. 277-284). IEEE.

[37] Moro, C., Štromberga, Z., \& Stirling, A. (2017). Virtualisation devices for student learning: Comparison between desktop-based (Oculus Rift) and mobile-based (Gear VR) virtual reality in medical and health science education. Australasian Journal of Educational Technology, 33(6).

[38] G. Kipper and J. Rampolla, Augmented Reality: An Emerging Technologies Guide to AR. Boston, MA: Syngress/Elsevier, 2013.

[39] Sardo, João DP, João AR Pereira, Ricardo JM Veiga, Jorge Semião, Pedro JS Cardoso, and João MF Rodrigues. "Multisensorial portable device for augmented reality experiences in museums." International Journal of Education and Learning Systems 3 (2018).

[40] Microsoft. What is mixed reality? https://docs.microsoft.com/enus/windows/mixed-reality/mixed-reality. (Accessed on 09/13/2019).

[41] https://www.acer.com/ac/en/US/content/series/wmr As on date $30 / 05 / 2020$

[42] https://store.hp.com/us/en/cv/mixed-reality-headset As on date $30 / 05 / 2020$

[43] Zheng, S.; Rosson, M.B.; Shih, P.C.; Carroll, J.M. Understanding student motivation, behaviors and perceptions in MOOCs. In Proceedings of the 18th ACM Conference on Computer Supported Cooperative Work \& Social Computing, Vancouver, Canada, 14-18 March 2015; pp. 1882-1895.

[44] Dewey, J. Experience and Education; Simon and Schuster: New York, NY, USA, 2007

[45] Yager, R.E. A vision for what science education should be like for the first 25 years of a new millennium. Sch. Sci. Math. 2000, 100, 327 341

[46] Zheng, S.; Rosson, M.B.; Shih, P.C.; Carroll, J.M. Understanding student motivation, behaviors and perceptions in MOOCs. In Proceedings of the 18th ACM Conference on Computer Supported Cooperative Work \& Social Computing, Vancouver, Canada, 14-18 March 2015; pp. 1882-1895.

[47] Nadan, T.; Alexandrov, V.; Jamieson, R.; Watson, K. Is virtual reality a memorable experience in an educational context? Int. J. Emerg. Technol. Learn. (iJET) 2011, 6, 53-57.
[48] Slavova, Y.; Mu, M. A comparative study of the learning outcomes and experience of VR in education. In Proceedings of the 2018 IEEE Conference on Virtual Reality and 3D User Interfaces (VR), Reutlingen, Germany, 18-22 March 2018; pp. 685-686.

[49] Cochrane, T. Mobile VR in education: From the fringe to the mainstream. Int. J. Mob. Blended Learn. (IJMBL) 2016, 8, 44-60.

[50] Christou, C. Virtual reality in education. In Affective, Interactive and Cognitive Methods for E-Learning Design: Creating an Optimal Education Experience; IGI Global: Hershey, PA, USA, 2010; pp 228-243.

[51] Petkovska, L.; Cvetkovski, G.; Kaminska, D.; Wiak, S.; FirychNowacka, A.; Lefik, M.; Sapinski, T.; Zwolinski, G.; Di Barba, P.; Mognaschi, M.E.; et al. ViMeLa PROJECT: An Innovative Concept for Teaching Students in Mechatronics Using Virtual Reality. In Proceedings of the 7th Symposium On Applied Electromagnetics (SAEM'18), Pod`cetrtek, Slovenia, 17-20 June 2018

[52] Pantelidis, V.S. Virtual reality and engineering education. Comput. Appl. Eng. Educ. 1997, 5, 3-12.

[53] Hurtado, C.V.; Valerio, A.R.; Sanchez, L.R. Virtual reality robotics system for education and training. In Proceedings of the Electronics, Robotics and Automotive Mechanics Conference (CERMA), Morelos, Mexico, 28 September 2010; pp. 162-167

[54] Serafin, S.; Adjorlu, A.; Nilsson, N.; Thomsen, L.; Nordahl, R. Considerations on the use of virtual and augmented reality technologies in music education. In Proceedings of the 2017 IEEE Virtual Reality Workshop on K-12 Embodied Learning through Virtual \& Augmented Reality (KELVAR), Los Angeles, CA, USA, 19 March 2017; pp. 1-4.

[55] F. Zund, M. Ryffel, S. Magnenat, A. Marra, M. Nitti, M. Kapadia, G. Noris, K. Mitchell, M. Gross, and R. W. Sumner, "Augmented creativity: bridging the real and virtual worlds to enhance creative play," pp. 1-7, 2015

[56] Mokhtar, Mohd Khalid, Farhan Mohamed, Mohd Shahrizal Sunar, Mohd Azhar M. Arshad, and Mohd Kufaisal Mohd Sidik. "Development of Mobile-Based Augmented Reality Colouring for Preschool Learning." In 2018 IEEE Conference on e-Learning, eManagement and e-Services (IC3e), pp. 11-16. IEEE, 2018.

[57] Y. Lee and J. Choi, "Texture extraction from video and image warping for ar coloring book," ser. Computer Science and its Applications. Springer Berlin Heidelberg, 2015, pp. 361-365.

[58] L. Feng, X. Yang, and S. Xiao, "Magictoon: A 2d-to-3d creative cartoon modeling system with mobile ar," in 2017 IEEE Virtual Reality (VR), 2017, pp. 195-204.

[59] M. Billinghurst, H. Kato, and I. Poupyrev, "Magicbook: transitioning between reality and virtuality," pp. 25-26, 2001.

[60] R. M. Yilmaz, S. Kucuk, and Y. Goktas, "Are augmented reality picture books magic or real for preschool children aged five to six?" British Journal of Educational Technology, vol. 48, no. 3, pp. 824$841,2017$.

[61] Amaia, Aguirregoitia Martínez, Allende López Iñigo, R. López Benito Jorge, and Artetxe González Enara. "Leihoa: A window to augmented reality in early childhood education." In 2016 International Symposium on Computers in Education (SIIE), pp. 1-6. IEEE, 2016.

[62] Bhadra, Arjun, Jamie Brown, Han Ke, Calvin Liu, Eun-Jeong Shin, Xikui Wang, and Alfred Kobsa. "ABC3D-Using an augmented reality mobile game to enhance literacy in early childhood." In 2016 IEEE international conference on pervasive computing and communication workshops (PerCom workshops), pp. 1-4. IEEE 2016.

[63] Wu, Hsin-Kai, Silvia Wen-Yu Lee, Hsin-Yi Chang, and Jyh-Chong Liang. "Current status, opportunities and challenges of augmented reality in education." Computers \& Education 62 (2013): 41-49.

[64] Schiavi, Barbara, Franck Gechter, Céline Gechter, and Albert Rizzo. "Teach Me A Story: an Augmented Reality Application for Teaching History in Middle School." In 2018 IEEE Conference on Virtual Reality and 3D User Interfaces (VR), pp. 679-680. IEEE, 2018.

[65] Yaman, Orhan, and Mehmet Karakose. "Development of image processing based methods using augmented reality in higher education." In 2016 15th International Conference on Information Technology Based Higher Education and Training (ITHET), pp. 1-5. IEEE, 2016.

[66] Reuter, Rebecca, Magdalena Beslmeisl, and Jürgen Mottok. "Work in progress: Teaching-obstacles in higher software engineering 
education." In 2017 IEEE Global Engineering Education Conference (EDUCON), pp. 1631-1635. IEEE, 2017.

[67] Paredes-Velasteguí, D., A. Lluma-Noboa, D. Olmedo-Vizueta, D. Avila-Pesantez, and J. Hernandez-Ambato. "Augmented reality implementation as reinforcement tool for public textbooks education in Ecuador." In 2018 IEEE Global Engineering Education Conference (EDUCON), pp. 1243-1250. IEEE, 2018.

[68] Alptekin, Mesut, and Katrin Temmen. "Design concept and prototype for an augmented reality based virtual preparation laboratory training in electrical engineering." In 2018 IEEE Global Engineering Education Conference (EDUCON), pp. 963-968. IEEE, 2018.

[69] Majeed, Asim, and Mahmood Ali. "How Internet-of-Things (IoT) making the university campuses smart? QA higher education (QAHE) perspective." In 2018 IEEE 8th Annual Computing and Communication Workshop and Conference (CCWC), pp. 646-648. IEEE, 2018.

[70] Y. C. Chen, "Peer learning in an AR- based learning environment," in 16th International Conference on Computers in Education, Taipei, Taiwan, 2008, pp. 291-295.

[71] D. Wagner, D. Schmalstieg, \& M. Billinghurst, "Handheld AR for Collaborative Edutainment," Advances in Artificial Reality and TeleExistence, pp. 85-96, 2006.

[72] F. W. Bruns: "Hyper Bonds," in Enabling Mixed Reality (82), 2001.

[73] D. Müller, F. W. Bruns, H. Erbe, B. Robben, Y. Yoo: "Mixed reality learning spaces for collaborative experimentation: A challenge for engineering education and training," in International Journal of Online Engineering 3 (4), pp. 15-19, 2007.

[74] Krishna, MV Pridhvi, Somesh Mehta, Shubham Verma, and Sagar Rane. "Mixed Reality in Smart Computing Education System." In 2018 International Conference on Smart Systems and Inventive Technology (ICSSIT), pp. 72-75. IEEE, 2018. 